\title{
Quantifying the Contribution of Organisms to the Provision of Ecosystem Services
}

GARY W. LUCK, RICHARD HARRINGTON, PAULA A. HARRISON, CLAIRE KREMEN, PAM M. BERRY, ROB BUGTER, TERENCE P. DAWSON, FRANCESCO DE BELLO, SANDRA DÍAZ, CHRISTIAN K. FELD, JOHN R. HASLETT, DANIEL HERING, ARETI KONTOGIANNI, SANDRA LAVOREL, MARK ROUNSEVELL, MICHAEL J. SAMWAYS, LEONARD SANDIN, JOSEF SETTELE, MARTIN T. SYKES, SYBILLE VAN DEN HOVE, MARIE VANDEWALLE, AND MARTIN ZOBEL

\begin{abstract}
Research on ecosystem services has grown rapidly over the last decade. Two conceptual frameworks have been published to guide ecological assessments of organisms that deliver services - the concepts of service-providing units (SPUs) and ecosystem service providers (ESPs). Here, we unite these frameworks and present an SPU-ESP continuum that offers a coherent conceptual approach for synthesizing the latest developments in ecosystem service research, and can direct future studies at all levels of organization. In particular, we show how the service-provider concept can be applied at the population, functional group, and community levels. We strongly emphasize the need to identify and quantify the organisms and their characteristics (e.g., functional traits) that provide services, and to assess service provision relative to the demands of human beneficiaries. We use key examples from the literature to illustrate the new approach and to highlight gaps in knowledge, particularly in relation to the impact of species interactions and ecosystem dynamics on service provision.
\end{abstract}

Keywords: ecosystem services, service-providing units, ecosystem service providers, biodiversity, functional diversity

\begin{abstract}
$\mathbf{E}^{\mathrm{c}}$ cosystem services, the benefits humans derive from ecosystems (table 1), are a subset of ecosystem processes that directly or indirectly support and improve human well-being (Daily 1997). Ehrlich and Ehrlich (1981) are usually credited with introducing the term "ecosystem services," but recognition of the contribution of nature to human well-being has a much longer history (Mooney and Ehrlich 1997). Nature contributes substantially to human well-being through a raft of services the Millennium Ecosystem Assessment (MEA 2003) classifies as provisioning services (e.g., food, water, fiber), regulatory services (e.g., flood mitigation, water purification), cultural services (e.g., recreation, aesthetic experiences), and supporting services needed for the production of all other ecosystem services (e.g., soil formation, nutrient cycling). Appropriate valuation of nature's contribution to humanity was central to early work in environmental economics (e.g., Krutilla 1967) and continues to be prominent in the current literature. For example, Boyd and Banzhaf (2007) argued for standardized units of account to measure the value of ecosystem services
\end{abstract}

to society. We echo this call, but from the perspective of delineating the ecological units needed to generate a given service. Ecologists have been slow in addressing this issue, which has stalled progress in the development of a truly integrated approach to measuring the contribution of nature to human well-being.

In this article, we present an approach to delineating and quantifying the contribution of organisms and ecological systems to service provision that unites and extends previous conceptual frameworks. We focus primarily on the generation of services and the key measures that deserve ecologists' attention, illustrating these through selected empirical examples. It is not possible to deal with every potential service, so we focus on those for which detailed empirical examples exist. We recognize the importance of social context to discussions of ecosystem services, but it is beyond the scope of this article to address this issue in detail. Nevertheless, by providing an explicit approach to measuring the ecological underpinnings of service provision, we hope to contribute to future advances in integrated, interdisciplinary assessments. 


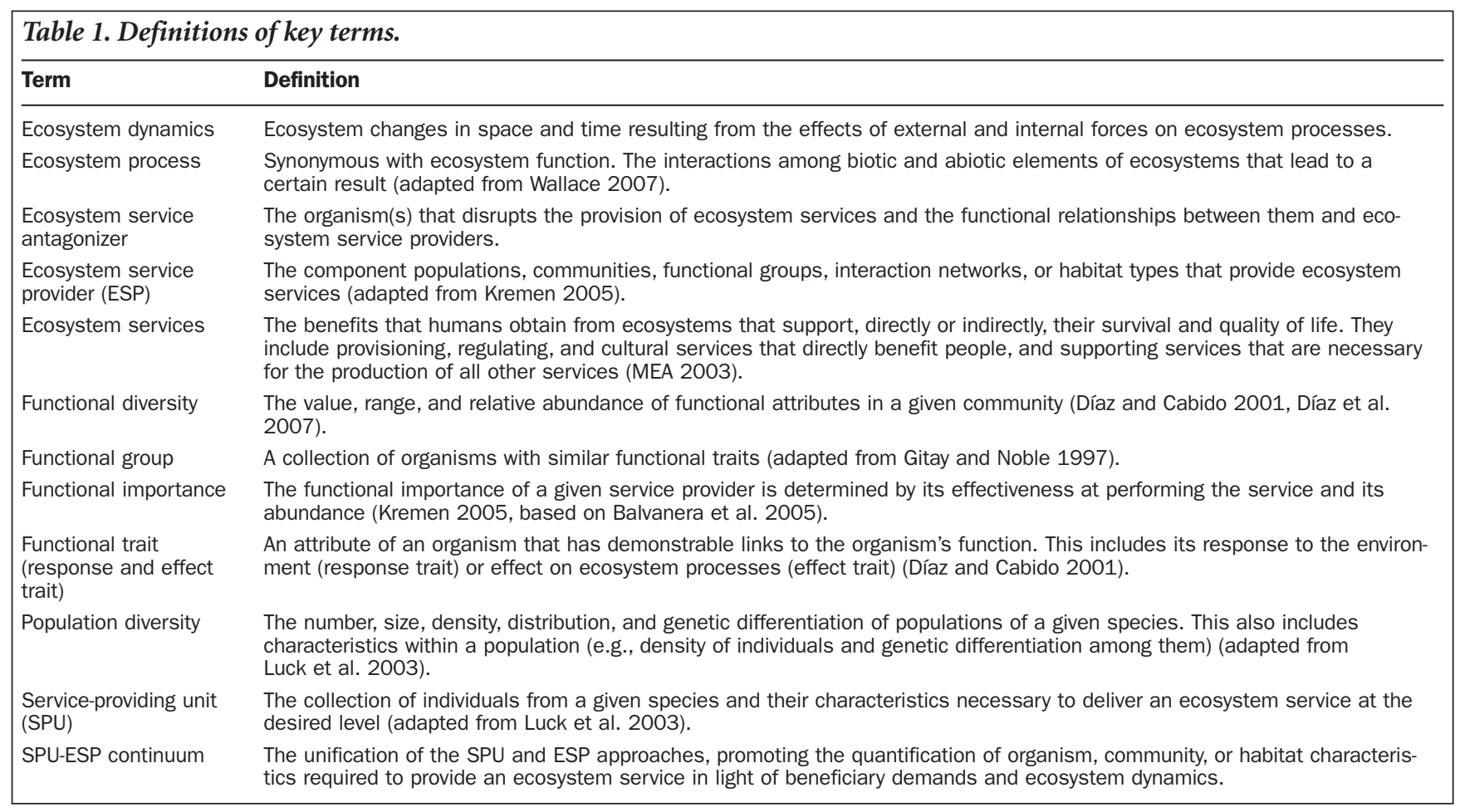

Research on the contribution of biodiversity to ecosystem services is in its infancy, but related work on the contribution of biodiversity to selected ecosystem processes is relatively well established. This research has emphasized the role that species and functional diversity play in modulating ecosystem processes such as primary production, nitrogen retention, decomposition, and stability (Díaz and Cabido 2001, Loreau et al. 2001, Tilman et al. 2006). This approach can be extended to include ecosystem services (e.g., Balvanera et al. 2006, Díaz et al. 2006), but a focus on diversity per se should not fail to include an understanding of the contribution that individual species, populations, and genotypes make to ecosystem services. Such an understanding can yield valuable insights into the implications of species' functional traits, behavior, and dynamics for service provision.

Two conceptual frameworks to guide ecological assessments of the delivery of services have been provided by Luck and colleagues (2003) and Kremen (2005) (see also Kremen et al. 2007, who focused specifically on service delivery by mobile organisms). Luck and colleagues (2003) argued that species populations are the fundamental unit contributing to services at the local level, where the provision and use of services is often most easily recognized. They introduced the concept of using service-providing units (SPUs) to explicitly link species populations with services and stressed that changes in population characteristics have implications for service provision. Kremen (2005) built on the SPU concept to identify key ecosystem service providers (ESPs) and to characterize the functional traits and functional importance of populations, communities, guilds, and interacting networks of organisms that deliver services.
The SPU concept evolved from the recognition that documenting changes in population diversity is a more comprehensive assessment of biodiversity status than a focus solely on changes in species richness or composition (Hughes et al. 1997). To conserve population diversity, we need to define the spatial and temporal extents of a population and determine the characteristics that should be used to measure diversity (e.g., population size, distribution, or genetic differentiation). Luck and colleagues (2003) argued that defining a population on the basis of its contribution to ecosystem services was most relevant to documenting the impact that changes in that population would have on human well-being. Moreover, a population boundary can be delineated by the extent over which a service is generated. Because it is logistically difficult—although not impossible— to apply the SPU approach to populations in real landscapes, Luck and colleagues (2003) pragmatically suggested that the concept could be extended beyond the population level to include within- or cross-taxon functional groups (guilds). Kremen (2005) extended this concept to include networks of interacting individuals and habitat types, and discussed various approaches for measuring the contributions of individual entities (SPUs or ESPs) or measuring function at an aggregate scale.

The SPU and ESP concepts thus represent a continuum that we unite in this article. This unification is timely, given the rapid evolution of ecosystem-service research in recent years. We review these developments using the united concepts (the SPU-ESP continuum, hereafter called simply the "serviceprovider" [SP] concept) to build an expanded conceptual framework for the study of biodiversity's contribution to ecosystem services. We use key examples from the literature to show how the SP concept can be applied across organiza- 
tional levels and to demonstrate how changes in the characteristics of service providers affect the delivery of services. We demonstrate the importance of understanding the form of the relationship between service-provider characteristics and service provision, particularly in relation to the needs of beneficiaries. It is vital to quantify the supply of ecosystem services relative to demand in a comprehensive assessment of service-provider contributions, but this subject is not covered in previous frameworks. We also show that understanding and managing species interactions, and ensuring that service providers are resilient to environmental variation, are crucial to maintaining the delivery of services.

These considerations lead to the development of a new conceptual model for the interactions among service providers, supporting systems, service provision, and societal and environmental changes. Throughout, we identify gaps in knowledge where more information is required to reduce uncertainties in our understanding of relationships among populations, species and community dynamics, and ecosystem services. We also acknowledge the need for contextual dependence and flexibility in defining service providers, as environmental variation, organism characteristics, and economic, policy, and social change can all interact in complex ways to influence the delivery and value of ecosystem services.

Our message is the following: identify and quantify the organisms and their characteristics that provide services, and determine how changes in these organisms affect service provision. Quantification is at the heart of the SP concept, and its value to policymakers and land managers is manifested through specific rather than vague management guidelines (Johst et al. 2006). Although ecosystem services are generated from myriad interactions occurring in complex systems, we need to understand at least some of the key relationships to manage the delivery of services effectively. Identifying key service providers can have enormous economic implications; for example, insect services in the United States alone are valued at $\$ 57$ billion per year (Losey and Vaughan 2006). The conceptual framework outlined here, which focuses on the areas most crucial for investigation, can guide future assessments of organisms' contributions to service provision across a continuum from populations to communities, habitat types, and landscapes. Our approach is applicable mainly at local scales, where the demand for and supply of ecosystem services are most easily quantified.

\section{The SPU-ESP continuum: From populations to communities}

The SPU-ESP continuum encompasses service providers across various organizational levels, from populations of single species to multispecies functional groups and ecological communities. The application of the conceptual framework, which is illustrated in the following case studies, relies on linking the most appropriate organizational level with a given service (or services). For example, species populations or functional groups are relevant primarily to services such as biological control or seed dispersal, whereas ecological communities or habitat types are pertinent to services such as flood mitigation, water regulation, and carbon storage.

The SP concept underscores the need to quantify the organism characteristics that are necessary to deliver a given ecosystem service. The approach also assumes that the (human) need for an ecosystem process has been explicitly identified, and that the rate of service delivery can vary but may need to meet some base level defined by service beneficiaries (e.g., financial profits attributable to service provision are above a given threshold). Put simply, we wish to know which sections of society use the service and at what level it is required, which organisms provide the service, and which characteristics of these organisms (e.g., density or distribution) are required to provide the service at the desired level.

In the SPU concept, the use of the word "unit" is a deliberate attempt to focus attention on the need to quantify the characteristics of the collection of organisms required for service provision, rather than simply to identify them. Moreover, delineating collections of organisms as SPUs and understanding the implications of their spatiotemporal dynamics for service provision may help to facilitate economic valuation of ecosystem services, which requires a quantifiable unit placed in a dynamic context (Boyd 2007). These important ideas are incorporated in the unified SP concept, although we acknowledge that our approach has varying applicability across all services influenced by factors such as scale and the capacity of various organisms to provide the same service.

\section{Populations within a single species}

Mols and Visser (2007) documented the capacity of great tits (Parus major) to provide a pest control service in apple orchards by substantially reducing caterpillar damage to the crop. At a density of one to six breeding pairs of birds per 2 hectares (ha), caterpillar damage is reduced by up to $50 \%$ compared with control sites with no breeding pairs (table 2). The density of breeding pairs is crucial because caterpillars are an important part of the bird's diet during this period, and they are a preferred food item for nestlings. It is therefore vital that the breeding season coincides with caterpillar activity and the stage of crop development, and that P. major is able to breed within or near apple orchards in sufficient densities (which can be facilitated by the provision of nest boxes in the orchard). The service provider in this example is at least one breeding pair of P. major every 2 ha within the apple orchard. However, it is not clear how service provision varies with incremental changes in breeding bird density (see below).

Mols and Visser (2007) did not explicitly quantify the need for this service by local landholders or the broader community, although they acknowledged that biological control of pests is growing in importance because of changes in public attitudes, evolution of pesticide resistance in insects, and legislative restrictions on pesticide use. Quantifying need is partly addressed by Hougner and colleagues (2006), who described the seed dispersal service provided by Eurasian jays (Garrulus glandarius) in oak forest in the National Urban Park of Stockholm, Sweden. First, they present general 


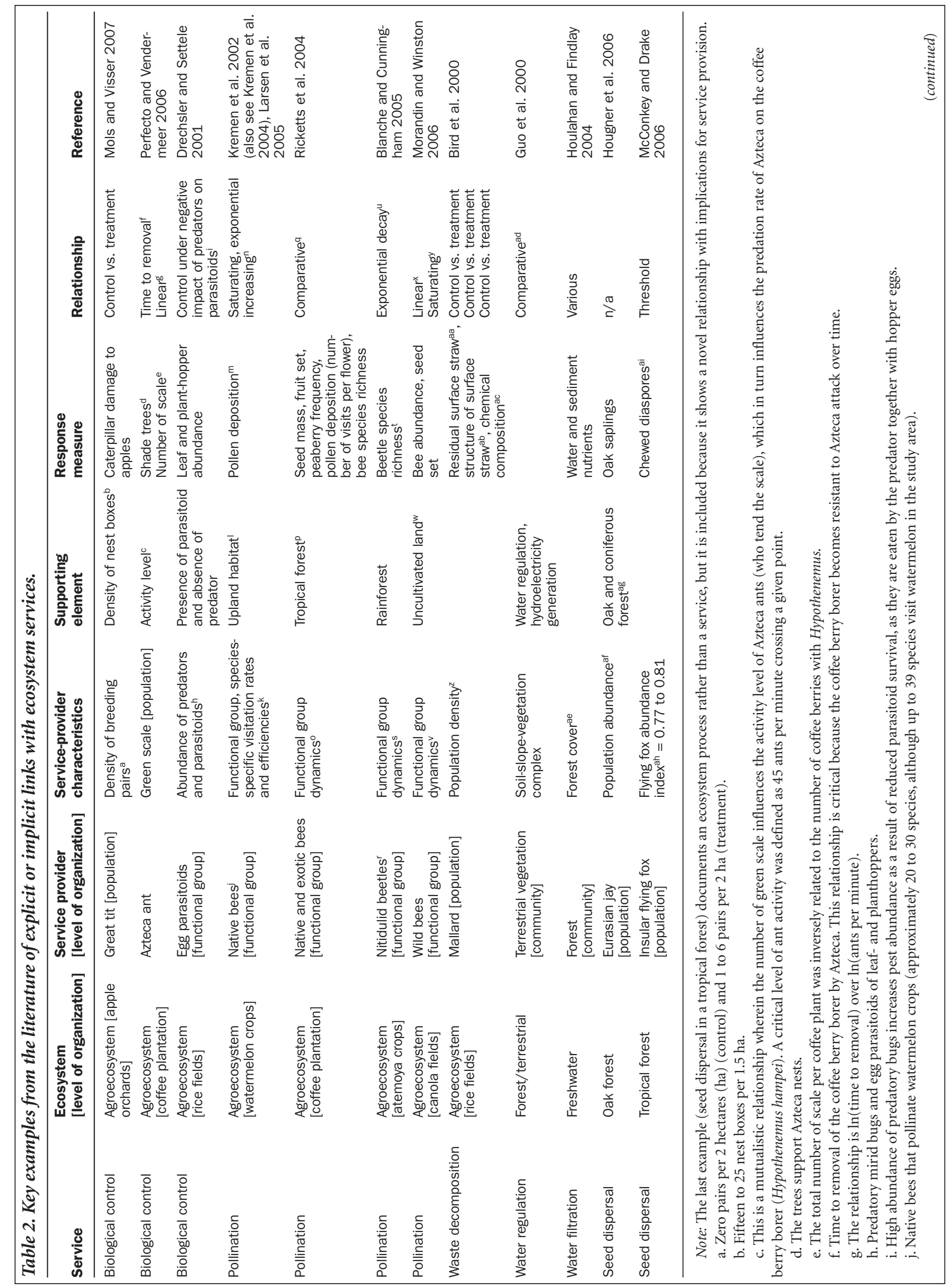




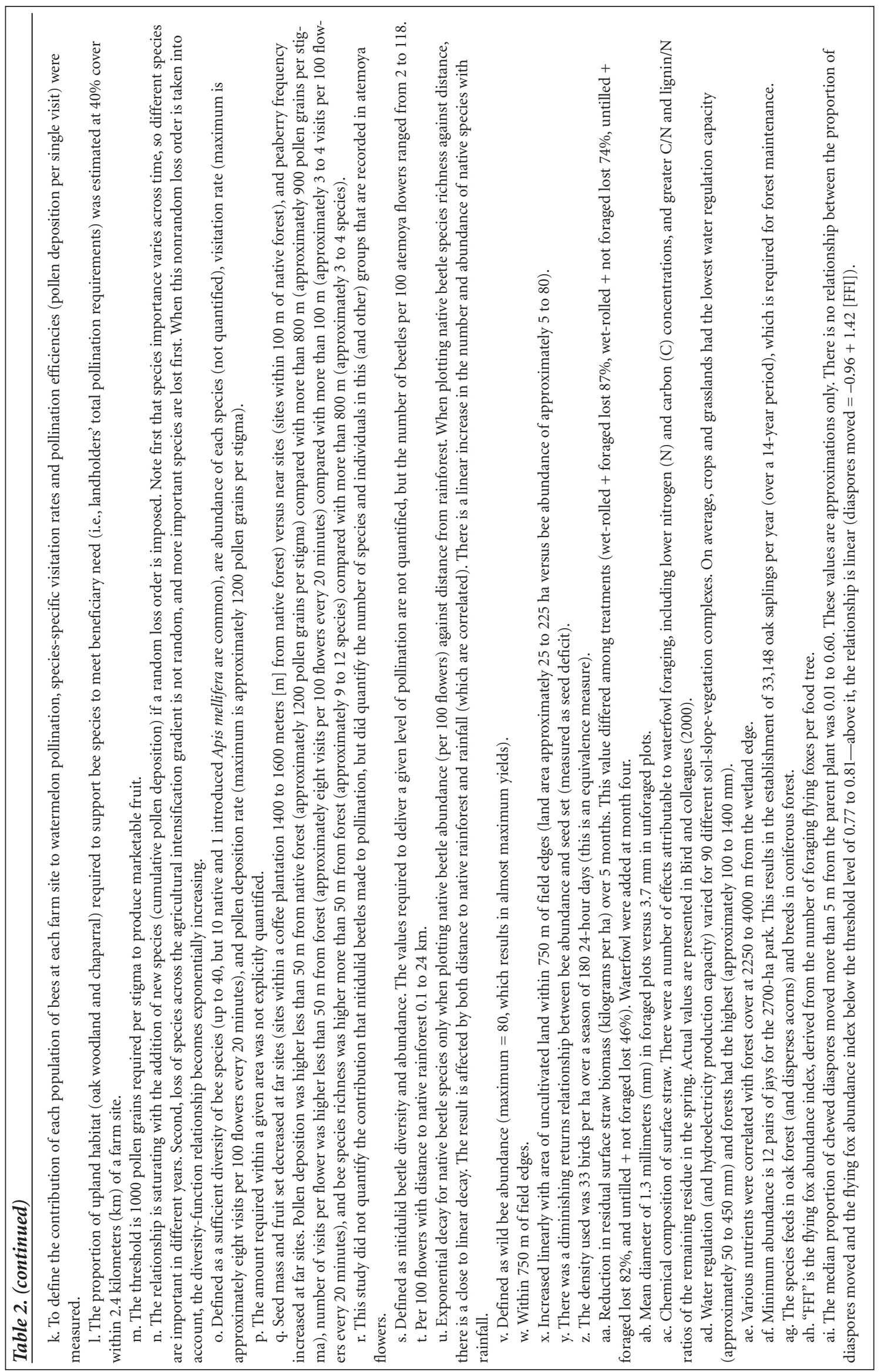


arguments about the cultural, recreational (e.g., 15 million visits per year), and biodiversity values of the park. They argue that oak forest makes a substantial contribution to these values, and, moreover, oaks (Quercus spp.) are recognized as keystone species in the region. Second, they show that the foraging and dispersal behavior of the jays facilitates acorn germination to an extent much greater than that of any other animal species in the park. Third, they estimate the replacement cost of the seed dispersal service provided by jays (i.e., the cost in dollars of seeding or planting oak trees by humans).

On the basis of an estimated average value of 33,148 oak saplings per year required for forest maintenance over a 14year period, Hougner and colleagues (2006) suggested that about 24 jays (or 12 pairs) would meet the seeding requirement. This number is a lower-bound estimate and does not consider the need to buffer jay populations against environmental change; the current jay population is estimated at 84 . The service provider minimum is 12 resident jay pairs present each year for 14 years. The replacement costs for the seed dispersal service provided by the jays were estimated at $\$ 4900$ (seeding) and \$22,500 (planting) per pair of jays. Although this example provides some convincing arguments demonstrating the need for and value of the ecosystem service, it is still not explicit how the loss of oak trees would affect the cultural, recreational, or biodiversity value of the park, or how these values change with incremental changes in the area of oak forest.

Other examples of service provision by populations within a single species are included in table 2 . By presenting singlespecies examples, we are not implying that other species could not provide these services or that interactions among the service provider and other organisms are not crucial to service provision. On the basis of current evidence, these are best viewed as examples of key service providers, analogous to the ecological concept of keystone species (Mills et al. 1993).

\section{Multispecies functional groups}

Service provision by functional groups has received particular attention (e.g., Kremen et al. 2002, Díaz et al. 2007) and was explored in detail by Kremen (2005). The SP concept reiterates and expands on Kremen's original ideas by arguing for the need to understand explicitly how characteristics manifested at the functional-group level (group composition) and for each member organism (population dynamics) affect service provision, and also by emphasizing a species' contribution to aggregate service, defined by its effectiveness at performing the service, and organism abundance.

For example, Kremen and colleagues (2002) showed that up to 30 native bee species contribute to pollinating watermelon plants in agricultural regions of California (table 2). Each species' contribution to crop pollination varied from one year to the next depending on changes in population abundances. Abundances varied from site to site on the basis of distance to native habitat and degree of agricultural intensification. The services provided by the pollinator guild depended on the guild's species composition-more specifically, on the functional traits of each member, the population characteristics of each member (e.g., density), and the appropriate spatial (e.g., distribution) and temporal (e.g., active during crop flowering) dynamics to deliver the service at the desired level.

Assuming that fluctuations among bee species populations are independent of one another, maintaining the diversity of the native pollinator guild is essential to service delivery because (a) the most functionally important species varied across time and space, such that more diverse guilds delivered more stable services (Kremen et al. 2002, 2004); (b) sites with more diverse guilds also had higher aggregate abundance due to a lack of density compensation (Larsen et al. 2005); and (c) the most efficient pollinators tended to occur in high but not low diversity guilds (Larsen et al. 2005).

Although it is possible to quantify the contributions of individual species populations to a service, as the above examples show, it is extremely challenging. It may be more pragmatic to measure an aggregate service benefit and relate it to guild characteristics (e.g., measuring fruit set and relating it to pollinator diversity measures rather than measuring species-specific functional traits such as pollination efficiencies; Klein et al. 2003). Moreover, management of service delivery may be more easily facilitated through an understanding of the relationships between habitat characteristics and service providers (e.g., by quantifying the amount of habitat needed to support the service providers; Kremen et al. 2004, Ricketts et al. 2004, Morandin and Winston 2006). For example, in California, Kremen and colleagues (2004) calculated that approximately $40 \%$ cover of upland habitat (oak woodland and chaparral) within 2.4 kilometers of a crop was required if the landholders wanted to obtain their entire pollination service from native bees. Hence, it is possible to differentiate between the service provider (the assemblage of native bee pollinators) and its supporting system - the amount of upland habitat required to conserve bee populations that provide a given level of service.

Quantifying the immediate support and habitat requirements of a service provider, especially for multispecies groups, may be a more feasible approach to managing service delivery because complex service-species interactions make it difficult to document the influence that change in any one species has on service provision. Moreover, concentrating on "supporting systems" is already generally accepted in conservation, and protection measures based on of the minimum habitat area required for the sustainability of populations are commonplace (e.g., Solomon et al. 2003). Further, this provides a clear role for policymakers who must develop planning strategies that protect regions that contribute substantially to service provision. Such strategies must consider the congruence between service protection and the conservation of the biodiversity that generates the services (Chan et al. 2006, Naidoo et al. 2008). This approach assumes a reasonable understanding of the relationships between supporting habitat, service providers, and service delivery, yet our 
knowledge of these interactions needs to be substantially improved.

\section{Ecological communities, habitat types, and landscapes}

The SP concept can be applied to ecological communities, habitat types, or landscapes. For example, Guo and colleagues (2000) demonstrated the differential capacity of terrestrial vegetation types to regulate water flow in Yangtze River watersheds, with concomitant implications for the production of hydroelectricity (table 2). They quantified four factors that may influence water regulation capacity: soil type, slope angle, vegetation type, and the area of each vegetation type. This resulted in 90 categories of vegetation-soil-slope complexes, with water flow regulation (and subsequently electricity production) differing substantially among complexes. Another general example is riparian vegetation buffers, which can control the influx of nutrients and soil into a river, reduce and filter surface runoff, and reduce stream-bank erosion (Dosskey 2001). The properties of the service provider are defined by the appropriate plant species or growth form composition; the width and location of the riparian buffer; and the vegetation zonation, density, and nutrient uptake rates (among other things) that are required to provide the service (Dosskey 2001, Correll 2005).

We include a nonexhaustive selection of examples of the SPU-ESP continuum in table 2. We exclude examples of relationships between species or functional diversity and ecosystem productivity, as these have been dealt with extensively elsewhere (e.g., Balvanera et al. 2006). Although it is clear that species and functional diversity per se can affect the provision of certain ecosystem services (Tilman 1996, Balvanera et al. 2006, Díaz et al. 2007), the SP approach argues for quantifying the relationships among service provision and key service providers, whether these are populations, functional groups, or ecological communities.

\section{Provider-beneficiary relationships}

So far we have described the SP approach primarily from the perspective of the providers without explicit recognition of the service beneficiaries' (i.e., humans') needs. Ecosystem services must be defined by both the contribution of service providers and the requirements of service beneficiaries to clearly document cost-benefit trade-offs (for conservation and production) associated with different land management options. There are various ways to approach this. It may be desirable to set a predetermined target whereby a collection of organisms are not considered as service providers unless they contribute a given amount to a particular service (e.g., a provider must contribute $30 \%$ to a pest control service, thereby reducing a land manager's reliance on pesticides and resulting in crop yields at a given profit margin). The benefits of this target approach include avoiding undue attention being placed on organisms that make insubstantial contributions to service provision (i.e., it identifies the key service providers). Moreover, at the level of populations within a single species, the SP concept could be considered analogous to the concept of minimum viable populations in conservation biology (Shaffer 1981). That is, a baseline value can be assigned to service providers that must be maintained to ensure service provision at a given level (e.g., minimum density, population abundance or genetic variance). This value must also consider ecosystem dynamics (see below) and the variability in demand for services by beneficiaries. In circumstances in which the conservation of service providers conflicts with production, designation of baseline targets may be largely unavoidable.

However, setting fixed targets is problematic because beneficiary demands change over time, and the approach potentially detracts from the need to understand how incremental changes in the characteristics of service providers affect service delivery. The latter is very important because it helps to identify the trade-offs in obtaining a given outcome through ecosystem services or anthropogenic alternatives (e.g., the costs and benefits along a continuum of options for controlling pests, based on various combinations of natural control from native or exotic species and pesticides). A series of curves can be envisaged that plot how changes in service-provider characteristics (e.g., population density) or anthropogenic alternatives affect a particular outcome (e.g., control of pests; figure 1). Of particular interest is the shape of the curve, or the portion of the curve, related to service provision by native organisms, as this illustrates the extent of their contribution and is most relevant to the contribution that protection of ecosystem services may make to biodiversity conservation. In the first two examples in figure $1(\mathrm{a}, \mathrm{b})$, native or native and exotic organisms contribute the entire service at the desired level. In the third example (figure 1c), native or exotic organisms do not provide the entire service, and a humanderived alternative is required to meet beneficiary needs (e.g., biocontrol + pesticide), but it is still important to quantify the extent of the contribution and its form (e.g., saturating).

For example, in Mols and Visser (2007) there was no relationship between the density of $P$. major breeding pairs and caterpillar damage to apples once the number of pairs exceeded one per $2 \mathrm{ha}$. Therefore, judging from a limited sample size, the relationship appears to be saturating. This could occur if the bird species supplements its diet with other prey, through competitive interactions with conspecifics, if a certain proportion of the caterpillar population is not available for consumption, or because pairs breed at different times of the season. Kremen and colleagues (2002) identified a saturating relationship between cumulative pollen deposition per flower and an increasing number of pollinators (also see Morandin and Winston 2006; table 2). That is, only a few species were needed to meet pollination demands for fruit production in watermelon crops; however, and most crucially, the identity of these species changed across time and space. Moreover, in this example, organic watermelon farms that were near pollinators' habitats received sufficient pollination services from native pollinators alone (i.e., comparable to the relationship in figure 1a), whereas organic farms far from pollinators' habitats or conventional farms received only a proportion of 
total pollination needs from native pollinators. Klein and colleagues (2003) identified a negative linear relationship between bee species diversity and distance to native forest, which resulted in a negative relationship between distance and the amount of fruit set in coffee plants. However, the latter is likely to be either a decelerating curve or threshold relationship, because although bee species provided additional pollination services within 1500 meters of the forest, a baseline level was maintained by wind pollination regardless of distance (Priess et al. 2007).

The need to identify the form of relationships between incremental change in service provider characteristics and service provision is applicable at all levels of organization and presents an approach that could possibly unify our understanding across levels. The challenge is to determine when particular relationships are likely to occur, whether generalizations can be identified (see Ricketts et al. 2008), and what implications the type of incremental change has for service provision. Moreover, the form of the relationship is mediated by organism characteristics and the needs of service beneficiaries. From the perspective of the latter, all relationships reach a threshold at the point when the level of need of service beneficiaries has been met (figure 1).

Understanding how incremental changes in particular characteristics of service providers affect service provision is analogous to determining the marginal benefits of protecting more of a certain habitat type that may provide particular services (Morandin and Winston 2006, Naidoo and Ricketts 2006). Priess and colleagues (2007) modeled the impact of future land-use scenarios on service provision and the economic value of coffee plantations, using relationships between pollination services and the distance to native forest (derived from Klein et al. 2003). Such approaches are vital for making informed choices among potential land uses (also see Guo et al. 2000, Steffan-Dewenter et al. 2007). However, the information required to build these models is largely unknown (Kremen et al. 2004, although see Drechsler and Settele 2001). There is a substantial need to collect information on how service provision changes as the characteristics of providers change along a continuum of variation, because those data are fundamental to land managers who need to decide among trade-offs attached to different management strategies (e.g., protecting habitat for service providers versus clearing a certain proportion for production).

\section{Species interactions}

To understand the dynamics of service providers, it is important to recognize the impact of intra- and interspecific interactions on service provision. These interactions include competition, commensalism, mutualism, and predatory interactions (e.g., carnivory and parasitism), and all have implications for service provision-especially when the service is provided by a key species or functional group. For example, Perfecto and Vandermeer (2006) showed how the abundance of the scale insect Coccus viridis and a mutualistic interaction with its attendant ant species Azteca instabilis influenced the degree of damage inflicted on coffee berries by the coffee berry borer Hypothenemus hampei (table 2). Greenleaf and Kremen (2006) found that behavioral interactions between native bees and the introduced honey bee Apis melli-
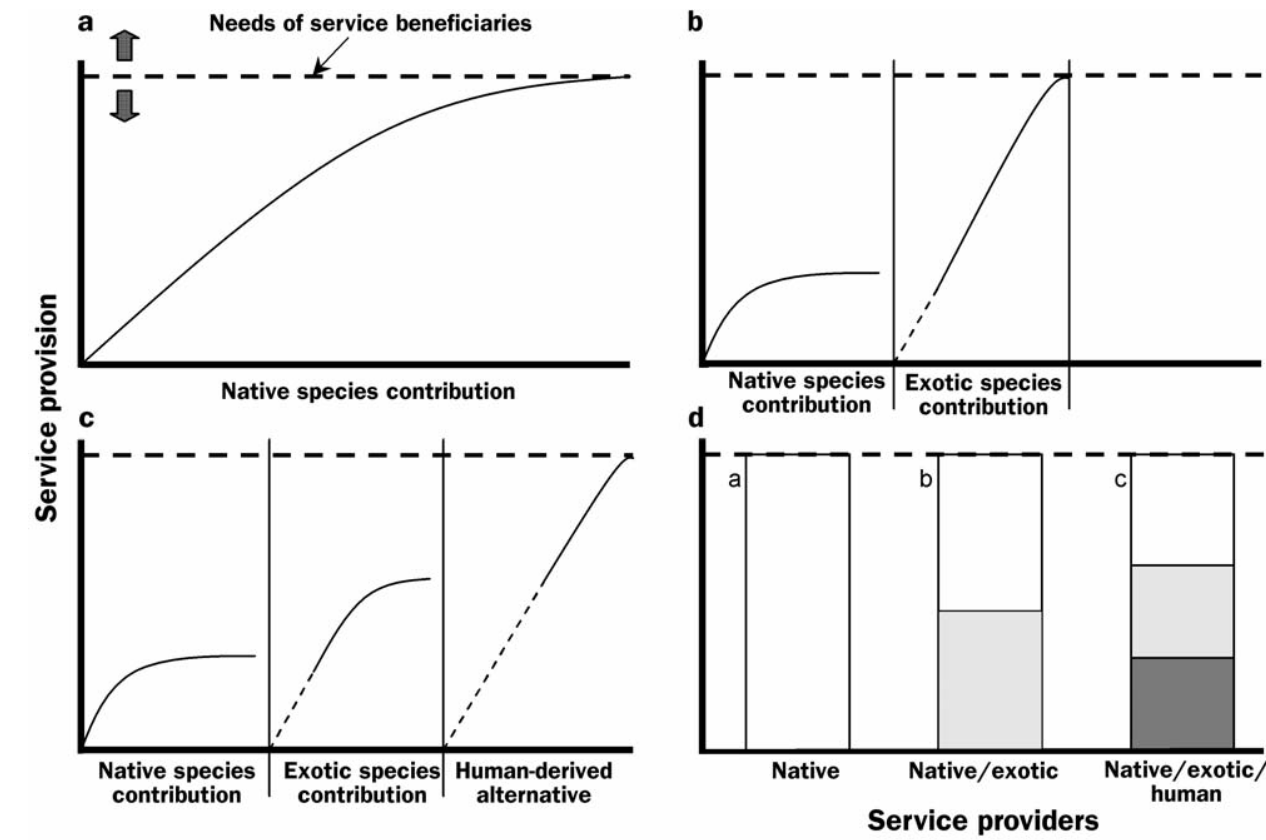

Figure 1. Theoretical relationships between service providers (SPs) and their contribution to service provision in relation to the needs of beneficiaries. (a) The service is provided entirely by native organisms with the shape of the "contribution curve" dictated by relationships between SP characteristics (e.g., density or genetic variance) and service delivery (i.e., a given density is required before beneficiary needs are met). Note that the needs of beneficiaries can fluctuate with changing socioeconomic conditions (see figure 2). (b) The contribution by native species asymptotes before beneficiary needs are met (see text for examples), with the remaining contribution provided by exotic species. Collectively, these are considered to be the SPs. The dashed line for exotic species indicates that these may provide the entire service in the absence of natives. (c) The contribution of both native and exotic species asymptotes and a human-derived alternative is required to meet needs. The final panel (d) summarizes the relationships in $a, b$, and $c$. 
fera enhanced the pollination efficiency (the number of seeds produced per visit) of the honey bee on hybrid sunflower $\mathrm{He}$ lianthus annuus. Interactions between the diversity of plants and mycorrhizae can be essential to primary productivity or nutrient cycling (e.g., van der Heijden et al. 1998).

Interactions that adversely affect service providers can have a negative impact on the delivery of ecosystem services. This depends on the nature of the interaction and the characteristics of both the service provider and the ecosystem service "antagonizer" (table 1). For example, the effects of biocontrol agents that have played a critical role in controlling insecticide-resistant red scale Aonidiella aurantii can be dramatically reduced by hyperparasitoids. The effectiveness of one of the parasitoids, Comperiella bifasciata, in controlling A. aurantii can even be reduced to zero by the impact of the hyperparasitoid Marietta leopardina (synonym Marietta javensis) (Samways 1985). However, this disruption to service provision can be circumvented by introducing another natural enemy, the ladybird Chilocorus nigritus, which is a very effective predator on the fully mature adult red scale, allowing other parasitoids to attack the younger stages. This complementary service provision has been quantified and modeled and has provided enormous economic benefit (Samways 1988; see Drechsler and Settele 2001 for a similar example).

In addition to the above example, organisms that provide a service in one context may disrupt the provision of another (or the same) service in a different context. For example, the activities of beavers (Castor spp.) in cold-water streams can enhance the productivity of economically important fish species, but the same species are not favored by beaver activities in warm-water streams (Collen and Gibson 2001). Alternatively, some service providers (e.g., pollinators) may promote the persistence of other species that provide additional ecosystem services (e.g., plants that control soil erosion; Kremen et al. 2007). An assessment of the service-providing value of organisms may need to consider trade-offs between service delivery, the support of additional services, and service disruption across a range of services.

It is easy to become bogged down in the complexity of these relationships. We argue that at the very least, we need to know something about the organisms and their characteristics that directly provide ecosystem services, and what is required to support them. We do not necessarily need to know about every interaction that leads to the existence of service providers-just enough to ensure their persistence. When it is not feasible to obtain detailed information about service-providing organisms, a practical way forward would be to focus on habitat or landscape management decisions that are more likely to promote organism protection (see above) or to ensure the persistence of particular functional traits within ecological communities (explained below).

\section{Ecosystem dynamics and resilience}

The value of the SP concept is greatly enhanced if some consideration is given to ecosystem dynamics. Ecosystems are in constant flux and it is crucial to ensure that systems have the capacity to cope with likely changes if ecosystem services are to be maintained. This is especially true if environmental variation leads to local extinctions or substantial fluctuations in population abundance. Researchers have approached this issue by focusing on the level of functional redundancy in a system, whereby a large number of species with a high degree of functional similarity should help to maintain a given ecosystem process in the light of environmental variability (Walker 1992). When multiple species contribute to the same ecosystem service, the stability of service provision should be, theoretically, buffered against fluctuations in the populations of the species constituting the effective functional group (Tilman et al. 1998). Multiple species contribution is an important system characteristic that may confer resilience to environmental change, where resilience is defined as the capacity of a system to cope with change through buffering, adaptation, and reorganization and still maintain crucial ecosystem processes (Elmqvist et al. 2003). However, it assumes a diversity of responses to environmental factors affecting functional group members and quantitatively similar contributions to service provision.

Resilience also implies functional replacement among species (i.e., when one species is lost, another is able to fill its functional role). Compensatory effects may be most evident among groups of species with short generation times, high mobility, extreme population fluctuations, or rapid turnover (e.g., many invertebrates and annual plants). For example, Walker and colleagues (1999) showed that processes relating to carbon and nutrient cycles should be maintained with increasing grazing pressure in Australian semiarid rangelands, because species replacement is made within a constant plant functional-trait space. Greater functional redundancy is expected at lower trophic levels (Loreau et al. 2001; e.g., soil organisms with short life cycles, Wertz et al. 2007), although this is not always the case (e.g., Drechsler and Settele 2001, Taylor et al. 2006).

Increased biodiversity is expected to contribute positively to ecosystem stability and secure continuation of ecosystem processes despite environmental variability (Tilman 1996). However, recent evidence suggests that the buffering effects of biodiversity are dependent on the type of disturbance and may be nonexistent in some circumstances (Balvanera et al. 2006). These effects remain poorly documented, including in agroecosystems where the buffering function of biodiversity against environmental variability or disturbances has been advocated as a key ecosystem service (Jackson et al. 2007). Nevertheless, a major problem in predicting the impacts of environmental changes on ecosystem services is the individualistic responses of service-providing organisms and the context-specific interactions among species in providing services. Defining service providers in terms of functional groups formed on the basis of their response traits and effect traits can circumvent this problem (Walker et al. 1999, Kremen 2005). The impact of environmental changes on service provision will then result from the overlap, co-occurrence, or linkage among response and effect traits of service providers 
(Díaz and Cabido 2001, Lavorel and Garnier 2002, Larsen et al. 2005). When effect traits can be identified and related to response traits, it is possible to predict changes in ecosystem services from the knowledge of species traits, expected changes in species abundance, and key abiotic factors (Díaz et al. 2007).

Species identity may be more important than diversity for some processes. We speculate that for long-lived species, an emphasis on maintaining populations of key species may be a more fruitful approach for the protection of ecosystem services than attempts to maximize diversity within a functional group (e.g., Jordano et al. 2007). If services are provided by populations of a key species, resilience may be maintained by ensuring that the species' life history (e.g., reproductive success) and population and genetic traits (e.g., variability) are appropriate to cope with likely changes in the environment. This approach is comparable to the concept of minimum viable populations, which are generally defined from a conservation perspective (e.g., the number of individuals needed to reduce the chances of extinction of a population to an acceptable level; Shaffer 1981). However, for the analogy to be appropriate, the SP concept must incorporate factors such as resilience to environmental variation, probability of persistence under future management scenarios, degrees of uncertainty, and acceptable levels of risk for loss of the service. For example, society may accept either a $1 \%$ or $5 \%$ probability of loss of a key service provider within 100 years, with the level of risk being determined by the consequences of service disruption. That is, it may be less acceptable to lose contributions to food production services than it is to lose recreational services.

In the context of populations within a single species, if a given service provider exists in a spatially disjunct collection of local populations across a region, then protecting service provision may rely on a degree of connectivity among these populations. This is relevant for mobile agent-based services such as pollination and pest control, where service providers are able to move among locations (Kremen et al. 2007). Spatially disjunct service-providing populations whose individuals have the potential for movement among populations are analogous to the ecological concept of metapopulation dynamics (Hanski 1999). If the local population of a service provider becomes functionally extinct (McConkey and Drake 2006), dispersal from adjacent populations may reinstate service provision and enhance species persistence. For example, the cultural services of large blue butterflies (different Maculinea species) can be maintained through appropriate management implicitly considering the metapopulation concept (Johst et al. 2006, Nowicki et al. 2007).

Ensuring the continuation of service provision requires consideration of the resilience of service providers to change and the maintenance of future options. Resilience is a relative term dependent on the interactions among ecosystems and the magnitude and types of environmental and anthropogenic pressures. For ecosystem services, greater resilience is required if there are substantial cultural, social, or eco- nomic implications of service provision failure. Sensitivity to environmental change and the implications of service disruption is a potential approach to prioritizing the protection of ecosystem services and their providers.

\section{A conceptual model of service provision}

There are many gaps in our knowledge about the ecological requirements for the delivery of services and about how environmental and anthropogenic change may affect service providers. Researchers rarely document explicitly the need for a given service and the implications of the loss of this service to beneficiaries (incorporating the availability of alternatives), which is vital if we are to identify appropriate service providers. We have little understanding of how changes in the characteristics of service providers affect the provision or the level of resilience required to maintain the delivery of services. Through decades of ecological research, we know more about the relationships between organisms and their supporting systems and how species interactions can influence behavior, although these are rarely placed in an ecosystem service context.

Although we have much to learn, the key relationships can be conceptualized to develop a model of service provision (figure 2). Ecosystem services emanate from complex relationships among beneficiaries, service providers, and the organisms or systems that support them. Several studies have demonstrated the role of indigenous habitat in supporting service providers such as native pollinators and quantified how changes in the area of this habitat (or changes in the distance to it) may affect service provision. Ricketts and colleagues (2008) synthesize results from these studies, which indicate that information on distance-pollination relationships is still lacking. Service providers can play a role in maintaining their support systems (e.g., bees pollinating wildflowers) and positive or negative species interactions can alter service providerprovision relationships (Greenleaf and Kremen 2006, Perfecto and Vandermeer 2006). Environmental and land-use change are major drivers of ecosystem processes and services (Díaz et al. 2007), and this can also affect demand for services. Moreover, market, cultural, and socioeconomic factors, and local, national, and international policy, will dictate the identity and requirements of service beneficiaries and drive environmental change (figure 2). This has direct and indirect impacts on the demands made of ecosystems and on the capacity of these systems to provide particular services.

We have not attempted to capture the complex social, cultural, or financial trends that drive market or policy change and their subsequent impact on the presence or type of service beneficiaries and their requirements. Moreover, the model is context specific, focusing on the delivery of a single service by designated service providers in a given landscape or seascape. For example, we do not include circumstances in which organisms might provide other services or support service provision by other organisms. Service provision occurs from a web of interactions analogous to food webs. 


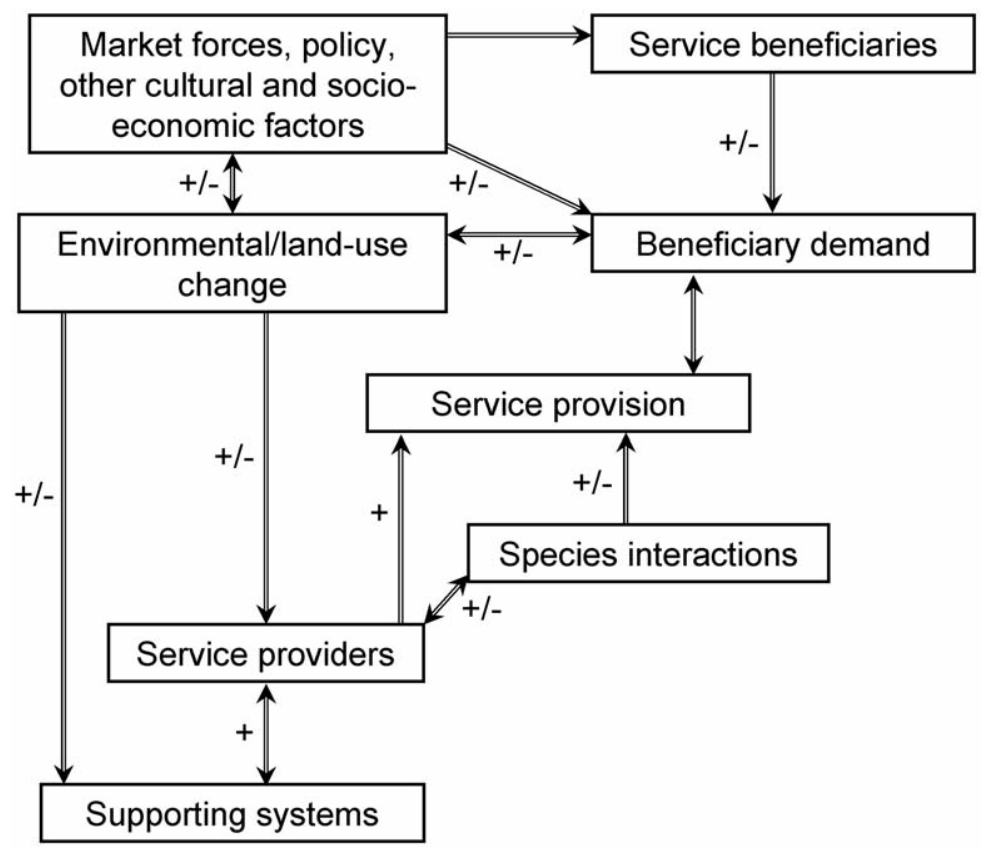

Figure 2. A conceptual model showing the links and positive or negative interactions among the socioeconomic and ecological factors of service provision. Cultural, social, and economic factors frame the needs of service beneficiaries and influence the demand for services. This demand is met through service provision, which is a result of service-provider characteristics, species interactions, and supporting systems. Environmental change, which is driven by but can also alter socioeconomic factors, has a substantial influence on the demand for services and the capacity of ecological systems to meet this demand.

\section{Conclusions}

Since the publication of the landmark text on ecosystem services (Daily 1997), we have made substantial progress in understanding the economic and social value of services and their ecological underpinnings. However, there is much to do, especially for the latter. We need to explore relationships between service providers and socioeconomic and environmental drivers of biodiversity change, and evaluate management strategies to ensure continued service provision. Also required is a framework to link indicators of environmental change to ecosystem dynamics and degradation, and to evaluate the suitability of these indicators for the assessment of ecosystem services using the SPU-ESP continuum.

The contribution that the protection of ecosystem services will make to biodiversity conservation is largely unknown, although is being increasingly explored through broadscale mapping (Chan et al. 2006, Naidoo and Ricketts 2006). In local case studies, research has focused mostly on how changes in particular characteristics (e.g., proportion of forest cover in a given area) affect service provision, without explicitly addressing whether maintenance of these characteristics will conserve service providers in the long term (Kremen et al. 2004, Ricketts et al. 2004, 2008). Reconciling species protection with service provision in a local context has, to our knowledge, not been addressed. Services provided by exotic species, or the notion of functional replaceability among species, potentially undermine the contribution that the ecosystem service approach can make to conservation. A ranking of species or systems on the basis of their service-providing value must be reconciled with considerations of resilience to environmental change and contribution to the conservation of indigenous biodiversity. The ecosystem service approach should never be considered as a replacement for traditional conservation strategies. However, we argue that the potential is great for the approach to add value to these strategies and act as a powerful force for species conservation in humandominated regions, particularly when the emphasis is on service provision by native species.

In this article, we have combined the two conceptual frameworks for studying the ecology of ecosystem service providers to synthesize our current understanding and provide guidance for future research. For the sake of simplicity, we focused on organisms or communities contributing to a single service. However, the SP concept could be applied to examinations of "bundles" of services (i.e., multiple services are provided by a collection of organisms). Moreover, a given organism may contribute to some services, be antagonistic toward the provision of others, support service provision by other organisms, or facilitate provision through interactions. Examining an organisms' role in the environment should consider the cost-benefit implications of all of its activities to human well-being.

\section{Acknowledgments}

This work was supported by the RUBICODE (Rationalising Biodiversity Conservation in Dynamic Ecosystems) Coordination Action Project funded under the Sixth Framework Programme of the European Commission (Contract no. 036890) and the Charles Sturt University special studies program. We thank three anonymous referees for insightful comments.

\section{References cited}

Balvanera P, Kremen C, Martínez-Ramos M. 2005. Applying community structure analysis to ecosystem function: Examples from pollination and carbon storage. Ecological Applications 15: 360-375.

Balvanera P, Pfisterer AB, Buchmann N, He J-S, Nakashizuka T, Raffaelli D, Schmid B. 2006. Quantifying the evidence for biodiversity effects on ecosystem functioning and services. Ecology Letters 9: 1146-1156.

Bird JA, Pettygrove GS, Eadie JM. 2000. The impact of waterfowl foraging on the decomposition of rice straw: Mutual benefits for rice growers and waterfowl. Journal of Applied Ecology 37: 728-741.

Blanche R, Cunningham SA. 2005. Rain forest provides pollinating beetles for atemoya crops. Journal of Economic Entomology 98: 1193-1201.

Boyd J. 2007. The endpoint problem. Resources 165: 26-28.

Boyd J, Banzhaf S. 2007. What are ecosystem services? The need for standardized environmental accounting units. Ecological Economics 63: 616-626. 
Chan KMA, Shaw MR, Cameron DR, Underwood EC, Daily GC. 2006. Conservation planning for ecosystem services. PLoS Biology 4: e379.

Collen G, Gibson RJ. 2001. The general ecology of beavers (Castor spp.) as related to their influence on stream ecosystems and riparian habitats, and the subsequent effects on fish-a review. Reviews in Fish Biology and Fisheries 10: 439-461.

Correll DL. 2005. Principles of planning and establishment of buffer zones. Ecological Engineering 24: 433-439.

Daily GC, ed. 1997. Nature's Services: Societal Dependence on Natural Ecosystems. Washington (DC): Island Press.

Díaz S, Cabido M. 2001. Vive la différence: Plant functional diversity matters to ecosystem processes. Trends in Ecology and Evolution 16: 646-655.

Díaz S, Fargione J, Chapin FS, Tilman D. 2006. Biodiversity loss threatens human well-being. PLoS Biology 4: e277.

Díaz S, Lavorel S, de Bello F, Quétier F, Grigulis K, Robson TM. 2007. Incorporating plant functional diversity effects in ecosystem service assessments. Proceedings of the National Academy of Sciences 104: 20684-20689.

Dosskey MG. 2001. Toward quantifying water pollution abatement in response to installing buffers on crop land. Environmental Management 28: 577-598.

Drechsler M, Settele J. 2001. Predator-prey interactions in rice ecosystems: Effects of guild composition, trophic relationships, and land use changesa model study exemplified for Philippine rice terraces. Ecological Modelling 137: 135-159.

Ehrlich P, Ehrlich A. 1981. Extinction: The Causes and Consequences of the Disappearance of Species. New York: Random House.

Elmqvist T, Folke C, Nyström M, Peterson G, Bengtsson J, Walker B, Norberg J. 2003. Response diversity, ecosystem change, and resilience. Frontiers in Ecology and the Environment 1: 488-494.

Gitay H, Noble IR. 1997. What are plant functional types and how should we seek them? Pages 3-19 in Smith TM, Shugart HH, Woodward FI, eds. Plant Functional Types: Their Relevance to Ecosystem Properties and Global Change. Cambridge (United Kingdom): Cambridge University Press.

Greenleaf SS, Kremen C. 2006. Wild bees enhance honey bees' pollination of hybrid sunflower. Proceedings of the National Academy of Sciences 103: 13890-13895.

Guo Z, Xiao X, Li D. 2000. An assessment of ecosystem services: Water flow regulation and hydroelectric power production. Ecological Applications 10: 925-936.

Hanski I. 1999. Metapopulation Ecology. Oxford (United Kingdom): Oxford University Press.

Houlahan JE, Findlay CS. 2004. Estimating the 'critical' distance at which adjacent land-use degrades wetland water and sediment quality. Landscape Ecology 19: 677-690.

Hougner C, Colding J, Söderqvist T. 2006. Economic valuation of a seed dispersal service in the Stockholm National Urban Park, Sweden. Ecological Economics 59: 364-374.

Hughes JB, Daily GC, Ehrlich PR. 1997. Population diversity: Its extent and extinction. Science 278: 689-692.

Jackson LE, Pascual U, Hodgkin T. 2007. Utilizing and conserving agrobiodiversity in agricultural landscapes. Agriculture, Ecosystems and Environment 121: 196-210.

Johst K, Drechsler M, Thomas JA, Settele J. 2006. Influence of mowing on the persistence of two endangered large blue butterfly species. Journal of Applied Ecology 43: 333-342.

Jordano P, García C, Godoy JA, García-Castaño JL. 2007. Differential contribution of frugivores to complex seed dispersal patterns. Proceedings of the National Academy of Sciences 104: 3278-3282.

Klein A-M, Steffan-Dewenter I, Tscharntke T. 2003. Fruit set of highland coffee increases with the diversity of pollinating bees. Proceedings of the Royal Society of London B 270: 955-961.

Kremen C. 2005. Managing ecosystem services: What do we need to know about their ecology? Ecology Letters 8: 468-479.

Kremen C, Williams NM, Thorp RW. 2002. Crop pollination from native bees at risk from agricultural intensification. Proceedings of the National Academy of Sciences 99: 16812-16816.
Kremen C, Williams NM, Bugg RL, Fay JP, Thorp RW. 2004. The area requirements of an ecosystem service: Crop pollination by native bee communities in California. Ecology Letters 7: 1109-1119.

Kremen C, et al. 2007. Pollination and other ecosystem services produced by mobile organisms: A conceptual framework for the effects of land-use change. Ecology Letters 10: 299-314.

Krutilla JV. 1967. Conservation reconsidered. American Economic Review 57: 777-786.

Larsen TH, Williams NM, Kremen C. 2005. Extinction order and altered community structure rapidly disrupt ecosystem functioning. Ecology Letters 8: 538-547.

Lavorel S, Garnier E. 2002. Predicting the effects of environmental change on plant community composition and ecosystem functioning: Revisiting the Holy Grail. Functional Ecology 16: 545-556.

Loreau M, et al. 2001. Biodiversity and ecosystem functioning: Current knowledge and future challenges. Science 294: 804-808.

Losey JE, Vaughan M. 2006. The economic value of ecological services provided by insects. BioScience 56: 311-323

Luck GW, Daily GC, Ehrlich PR. 2003. Population diversity and ecosystem services. Trends in Ecology and Evolution 18: 331-336.

McConkey KR, Drake DR. 2006. Flying foxes cease to function as seed dispersers long before they become rare. Ecology 87: 271-276.

[MEA] Millennium Ecosystem Assessment. 2003. Ecosystems and their services. Pages 49-70 in Ecosystems and Human Wellbeing: A Framework for Assessment. Washington (DC): Island Press.

Mills LS, Soulé ME, Doak DF. 1993. The keystone-species concept in ecology and conservation. BioScience 43: 219-224.

Mols CMM, Visser ME. 2007. Great tits (Parus major) reduce caterpillar damage in commercial apple orchards. PLoS One 2: e202.

Mooney HA, Ehrlich PR. 1997. Ecosystem services: A fragmentary history. Pages 11-19 in Daily GC, ed. Nature's Services: Societal Dependence on Natural Ecosystems. Washington (DC): Island Press.

Morandin LA, Winston ML. 2006. Pollinators provide economic incentive to preserve natural land in agroecosystems. Agriculture, Ecosystems and Environment 116: 289-292.

Naidoo R, Ricketts TH. 2006. Mapping the economic costs and benefits of conservation. PLoS Biology 4: e360.

Naidoo R, Balmford A, Costanza R, Fisher B, Green RE, Lehner B, Malcolm TR, Ricketts TH. 2008. Global mapping of ecosystem services and conservation priorities. Proceedings of the National Academy of Sciences 105: 9495-9500.

Nowicki P, Pepkowska A, Kudlek J, Skórka P, Witek M, Settele J, Woyciechowski M. 2007. From metapopulation theory to conservation recommendations: Lessons from spatial occurrence and abundance patterns of Maculinea butterflies. Biological Conservation 140: 119-129.

Perfecto I, Vandermeer J. 2006. The effect of an ant-hemipteran mutualism on the coffee berry borer (Hypothenemus hampei) in southern Mexico. Agriculture, Ecosystems and Environment 117: 218-221.

Priess JA, Mimler M, Klein A-M, Schwarze S, Tscharntke T, SteffanDewenter I. 2007. Linking deforestation scenarios to pollination services and economic returns in coffee agroforestry systems. Ecological Applications 17: 407-417.

Ricketts TH, Daily GC, Ehrlich PR, Michener CD. 2004. Economic value of tropical forest coffee production. Proceedings of the National Academy of Sciences 101: 12579-12582.

Ricketts TH, et al. 2008. Landscape effects on crop pollination services: Are there general patterns? Ecology Letters 11: 499-515.

Samways MJ. 1985. Relationship between red scale, Aonidiella aurantii (Maskell) (Hemiptera: Diaspididae), and its natural enemies in the upper and lower parts of citrus trees in South Africa. Bulletin of Entomological Research 75: 379-393.

-1988. A pictorial model of the impact of natural enemies on the population growth rate of the scale insect Aonidiella aurantii. South African Journal of Science 84: 270-271.

Shaffer ML. 1981. Minimum population sizes for species conservation. BioScience 31: 131-134. 
Solomon M, Van Jaarsveld AS, Biggs HC, Knight MH. 2003. Conservation targets for viable species assemblages? Biodiversity and Conservation 12 2435-2441.

Steffan-Dewenter I, et al. 2007. Tradeoffs between income, biodiversity, and ecosystem functioning during tropical rainforest conversion and agroforestry intensification. Proceedings of the National Academy of Sciences 104: 4973-4978.

Taylor BW, Flecker AS, Hall RO. 2006. Loss of a harvested fish species disrupts carbon flow in a diverse tropical river. Science 313: 833-836.

Tilman D. 1996. Biodiversity: Population versus ecosystem stability. Ecology 77: $350-363$.

Tilman D, Lehman CL, Bristow CE. 1998. Diversity-stability relationships: Statistical inevitability or ecological consequences? American Naturalist 151: 277-282.

Tilman D, Reich PB, Knops JMH. 2006. Biodiversity and ecosystem stability in a decade-long grassland experiment. Nature 441: 629-632.

van der Heijden MGA, Klironomos JN, Ursic M, Moutoglis P, StreitwolfEngel R, Boller T, Wiemken A, Sanders IR. 1998. Mycorrhizal fungal diversity determines plant biodiversity, ecosystem variability and productivity. Nature 396: 69-72.

Walker BH. 1992. Biodiversity and ecological redundancy. Conservation Biology 6: 18-23.

Walker BH, Kinzig A, Langridge J. 1999. Plant attribute diversity, resilience, and ecosystem function: The nature and significance of dominant and minor species. Ecosystems 2: 95-113.

Wallace KJ. 2007. Classification of ecosystem services: Problems and solutions. Biological Conservation 139: 235-246.

Wertz S, Degrange V, Prosser JI, Poly F, Commeaux C, Guillaumaud N, Le Roux X. 2007. Decline of soil microbial diversity does not influence the resistance and resilience of key soil microbial functional groups following a model disturbance. Environmental Microbiology 9: 2211-2219.

Gary W. Luck (e-mail: galuck@csu.edu.au) is with the Institute for Land, Water and Society at Charles Sturt University in Albury, Australia. Richard Harrington is with the Centre for Bioenergy and Climate Change, Department of Plant and Invertebrate Ecology, Rothamsted Research, in Hertfordshire,
United Kingdom. Paula A. Harrison and Pam M. Berry are with the Environmental Change Institute at the Oxford University Centre for the Environment in Oxford, United Kingdom. Claire Kremen is with Environmental Sciences Policy and Management at the University of California, Berkley. Rob Bugter is with the Wageningen University and Research Centre in Wageningen, The Netherlands. Terence P. Dawson is with the School of Geography at the University of Southampton in Highfield, United Kingdom. Francesco de Bello and Sandra Lavorel are with the Laboratoire d'Ecologie Alpine at the Université Joseph Fourier in Grenoble, France. Sandra Díaz is with the Instituto Multidisciplinario de Biología Vegetal and the Facultad de Ciencias Exactas, Físicas y Naturales de la Universidad Nacional de Córdoba in Argentina. Christian K. Feld and Daniel Hering are with the Department of Applied Zoology/Hydrobiology at the University of Duisburg-Essen in Germany. John R. Haslett is with the Department of Organismal Biology, Division of Zoology and Functional Anatomy, at the University of Salzburg in Austria. Areti Kontogianni is with the Department of Environmental Studies and the Department of Marine Sciences at the University of the Aegean, Greece. Mark Rounsevell is with the Centre for Environmental Change and Sustainability of the University of Edinburgh, United Kingdom. Michael J. Samways is with the Department of Conservation Ecology and Entomology, and the Centre for Agricultural Biodiversity, Faculty of AgriSciences, at the University of Stellenbosch in South Africa. Leonard Sandin is with the Department of Environmental Assessment at the Swedish University of Agricultural Sciences in Uppsala, Sweden. Josef Settele is with UFZ-Helmholtz Centre for Environmental Research, Department of Community Ecology, in Halle, Germany. Martin T. Sykes and Marie Vandewalle are with the Department of Physical Geography and Ecosystems Analysis at Lund University, Sweden. Sybille van den Hove is with Median SCP and the Institut de Ciència i Tecnologia Ambientals at the Universitat Autònoma de Barcelona in Spain. Martin Zobel is with the Institute of Ecology and Earth Sciences at the University of Tartu in Estonia. 